DOI: http://dx.doi.org/10.17793/rdd.v3i5.553

\title{
6. A CLÁUSULA PENAL APOSTA NO CONTRATO DE FIANÇA A TÍTULO DE GARANTIA DO CONTRATO DE EMPRÉSTIMO NA MODALIDADE DE MÚTUO, A PARTIR DA OBRA DE SHAKESPEARE, O MERCADOR DE VENEZA
}

\author{
6. THE CRIMINAL BET CLAUSE ON GUARANTEE AGREEMENT AS A LOAN AGREEMENT ON \\ WARRANTY LOAN TYPE, FROM SHAKESPEARE'S WORK, THE MERCHANT OF VENICE
}

Antônio Maria de Freitas Iserhard ${ }^{1}$

\begin{abstract}
Resumo: Este artigo apresenta uma análise sobre a cláusula penal aposta no contrato de fiança a título de garantia do contrato de empréstimo na modalidade de mútuo, com vistas a uma contribuição à hermenêutica jurídica na arte de interpretação, integração e aplicação do direito dos contratos, a partir da obra de Shakespeare, O Mercador de Veneza.
\end{abstract}

Palavras-chave: Fiança, Mercador de Veneza, hermendêutica.

Abstract: This article presents an analysis of the penalty clause in the contract of guarantee commitment under the guarantee of the loan agreement, with the aim of contributing to to legal hermeneutics in the art of interpretation, integration and application of contract law, leading into acccount the work of Shakespeare, the Merchant of Venice.

Keywords: Guarantee, Merchant of Venice, hermeneutics

\section{Síntese histórica}

Versa a peça de Shakespeare sobre a amizade, o amor, a confiança, as metáforas, a vingança, o mito, a religião, a ideologia, o utilitarismo, a justiça, o direito, enfim sobre os mais variados sentimentos despertados no gênero humano. Trata-se de um empréstimo de três mil ducados, na modalidade de mútuo, feito pelo judeu Schylock à Bassânio, amigo do cristão Antônio, o qual assinou perante o notário uma

\footnotetext{
${ }^{1}$ Doutor em Direito, professor da disciplina de Direito Civil V - Contratos em Espécie, pesquisador na Faculdade de Direito, Cesuca, Desembargador do Tribunal de Justiça do RS. E-mail: aiserhard@tj.rs.gov.br 
letra, nota promissória, a título de fiança, na qual se obrigava a pagar com uma libra de carne de seu próprio corpo, acaso não cumprida a obrigação principal no seu vencimento, que se daria no prazo de três meses.

Antônio, fiando-se no seu patrimônio, composto por uma frota de quatro navios mercantes, não contava com a possibilidade de não ter a soma afiançada na data aprazada, o que fatalmente acabou acontecendo, pois seus navios não retornaram a tempo de apurar a quantia prometida em garantia, o que acarretou no inadimplemento da obrigação. Por sua vez, Schylock que havia feito o empréstimo à Bassânio, sem outra condição, nem mesmo juros, para o caso de incumprimento contratual, à exceção de ter como garantia o aval na própria pessoa de Antônio, a quem o tinha por inimigo, dado na sua atividade de coletor de impostos reduzir a taxa de juros e por que emprestava de graça, o que prejudicava Schylock.

Portanto, Schylock movido pelo ódio, aceitou a multa cegado pela possibilidade de exercer pessoalmente sua vindita na pessoa de Antônio, que somente não levou adiante seu intento, mercê da habilidade jurídica do advogado Baltasar, em cujo personagem se travestiu Pórcia, a prometida em casamento de Bassânio por obra do destino pela sorte na abertura do porta jóia de chumbo determinada pela vontade testamentária de seu genitor, dado seu tirocínio jurídico e capacidade argumentativa, que não somente livrou Antônio da multa, bem como obteve uma punição para Schylock, valendo-se de uma interpretação sistemática e semiológica do direito, denunciando a própria incompletude das palavras, sua vagueza e ambigüidade, revelando o poder da linguagem do direito, a partir de um enfoque sintático, semântico e pragmático de sentido, enfim argumentando juridicamente.

\section{Texto}

A leitura de uma obra não denota um significado unívoco. Há várias leituras de um mesmo texto. E cada leitura é uma releitura. De modo que a leitura da obra $O$ Mercador de Veneza sugere as mais diversas leituras e releituras. Neste sentido, a peça de Sheakespeare ao retratar a fiança prestada pelo cristão Antônio em garantia ao empréstimo obtido por seu amigo Bassânio perante o judeu Schylock, sem condições, juros, apenas a fixação de uma multa exata de uma libra de carne a ser tirada de qualquer parte do corpo do fiador, no caso de inadimplemento da obrigação principal no seu termo, consistente no mútuo, inspira tanto uma leitura sob o ponto de vista dos direitos humanos, dado a inusitada cláusula aposta na nota promissória, em 
garantia do empréstimo, fazendo incidir o aval no próprio corpo do fiador, na previsão contratual de extração de uma libra de carne humana para o caso de não haver o resgate do empréstimo, o que constitui afronta à dignidade da pessoa humana, princípio reitor e fundamento do estado democrático de direito.

Se está diante de cláusula na perspectiva das transformações experimentadas na ordem constitucional dos países que adotaram os ideários das grandes revoluções, mesmo ainda que considerando o viés temporal em que escrita a peça, pelo que convém não deslembrar de que há muito o devedor e/ou fiador não responde mais com o seu corpo pelo cumprimento das obrigações, mas sim com o seu patrimônio.

Suscita ainda a leitura sob a ótica religiosa, sua (in)tolerância, na medida em que o mutuante e o fiador são, respectivamente, judeu e cristão, o que ensejaria uma reflexão sobre o dogma, a crença, o sentimento de religiosidade, o perdão, a misericórdia, o utilitarismo, etc., porquanto o que motivou o judeu a emprestar não foi o sentimento de ajuda ao próximo, tendo inclusive aliviado o mutuário do pagamento de juros, mas sim pela inescondível situação de poder contar com a possibilidade do incumprimento da obrigação no prazo azado de três meses e daí poder voltar-se contra o fiador, a que o tinha como inimigo, em razão de o garante no exercício da sua atividade de coletor emprestar de graça e reduzir os juros que o mutuante cobrava de quem obtinha empréstimo consigo.

Portanto, era a oportunidade esperada pelo judeu para dar a desforra ao cristão, impelido pelo ódio que nutria por ele e assim não cometer o perjúrio de haver jurado pelo Sabá sagrado de recolher a multa que Ihe era devida. Uma outra leitura possível seria sobre os sentimentos, a amizade, o amor, a vingança, a justiça, o que leva um amigo a assumir com a própria pele a garantia de uma dívida contraída por empréstimo, ainda que sabedor das conseqüências que poderiam advir, no caso da impontualidade do pagamento. Aqui também podemos ser levado a uma reflexão sobre o dilema humano colocado por Hobbes e Rousseau se o homem é mau ou bom por natureza como, respectivamente defendem ou seja o homem é o lobo do outro homem ou o homem nasce bom e a sociedade o corrompe, esta última visão encarnada no bom selvagem de Rousseau.

Ainda outra leitura possível seria sob o prisma da semiologia, haja vista que a linguagem jurídica empregada pelo causídico Baltasar, personagem em que se traveste Pórcia, esgrima com maestria a semiologia, numa abordagem sintática, semântica e pragmática, com os usos lingüísticos emotivo e cognoscitivo, procurando 
infundir no relutante Schylock argumentos de índole religiosa e na medida em que tais se mostraram insuficientes não hesitou em lançar mão de argumentos jurídicos, valendo-se da hermenêutica jurídica para convencer o credor da impossibilidade de cobrar a multa na exata medida em que ela fora compromissada, atentando ainda para uma visão sistemática da ordem jurídica, denunciando que a cláusula penal como aposta, confessadamente por brincadeira, mas para dar vazão ao sentimento vingativo do judeu, estaria a atentar contra a vida de um cidadão vienense por um estrangeiro, o que encontra punição severa no ordenamento jurídico.

Assim, nem mesmo a interpretação literal da cláusula penal se sustentou, o que revela a vagueza e a ambigüidade de que se ressentem as palavras da lei, que por serem vazadas numa linguagem pretensamente técnica, não conseguem eliminá-las. De igual maneira, demonstrou Baltazar, intérprete e aplicador da norma positivada, além do elastério da diç̧ão da cláusula contratual, a integração que deve ser procedida quando da aplicação do direito, recorrendo a uma interpretação sistemática do direito.

Aliás, a exemplo do que já ensinara Rudolf Von Stammler, é impossível ler um artigo de lei isoladamente, pelo que se deve atentar para todo o sistema normativo. Somente a argumentação jurídica foi apta a infundir em Schylock a crença da impossibilidade jurídica de cobrar a multa tal como posta em garantia.

Enfim, uma outra leitura possível e que se nos afigura pertinente com a disciplina por nós lecionada no Curso de Graduação em Direito da Cesuca, Direito Civil V Contratos em Espécie - é a sob o enfoque jurídico e que nos leva a refletir sobre a natureza da cláusula penal, multa, presente no contrato acessório de fiança representado pela nota promissória assinada por Antônio perante o notário na condição de garante do contrato de empréstimo, na espécie de mútuo, que o mutuante Schylock concedeu a Bassânio, amigo de Antônio.

Ora, no estudo analítico a ser empreendido sobre a referida cláusula penal, não descurando das outras leituras possíveis que tocam o presente estudo, será levado em consideração, principalmente, a leitura semiológica, na medida em que a hermenêutica jurídica da multa fixada implica em interpretar, integrar, corrigir e aplicar o direito, o que envolve os usos da linguagem emotivo e cognoscitivo, a partir de um enfoque semiológico sintático, semântico e pragmático.

Consoante emerge da leitura do texto, a obrigação principal consiste no contrato de empréstimo, na modalidade de mútuo, que o judeu Schylock faz à Bassânio de três 
mil ducados, para pagamento no lapso de três meses. A obrigação acessória residente no contrato de fiança, consiste no aval do próprio corpo do cristão Antônio prestado em garantia do cumprimento da obrigação principal, que foi o empréstimo de três mil ducados feito por Schylock ao amigo de Antônio, Bassânio. A multa estava assim redigida na letra, nota promissória: se Antônio não pagar o que deve no dia previsto, no local previsto, tal quantia ou quantias como descritas na promissória, que seja a multa exatamente uma libra de sua carne clara, a ser cortada e tirada de qualquer parte do seu corpo que eu nominar.

Prescindindo da ilicitude do objeto da prestação dado em garantia, haja vista que do ponto de vista do direito positivo hodierno tal cláusula se afigura nula de pleno direito, por se tratar de objeto ilícito, razão pela qual não pode ser vinculada ao cumprimento da obrigação principal, consistente no empréstimo efetuado, de modo que referida obrigação de dar coisa certa não produz efeitos jurídicos, pois de há muito que o devedor não responde mais com o seu corpo pelo incumprimento das obrigações, senão com o seu patrimônio, porquanto pelo inadimplemento das obrigações respondem todos os bens do devedor, pelo que não podia mesmo o aval, a fiança, incidir sobre a própria pessoa, obrigando-o com o próprio corpo, comporta analisar o teor da obrigação acessória como se existente, válida e eficaz o fosse.

O fato é que Antônio emprestara o corpo pelo amigo Bassânio e se não fosse pela habilidade jurídica do advogado Baltasar, personagem em que se travestiu a personagem Pórcia, teria perdido o próprio corpo, pois na hipótese imaginada as leis de Veneza não permitiam o descumprimento dos pactos, para evitar o precedente e o consequente enfraquecimento do próprio comércio com os estrangeiros, por isso mesmo que o Doge, arvorado em juiz, não podia mesmo ter permitido a violação do princípio do pacta sunt servanda, no qual se acham insculpidos os princípios da autonomia da vontade, da liberdade de contratar e do relativismo jurídico, apesar de não ter medido esforços para suavizar a intransigente obstinação de Schylock, que nem mesmo cedera ante a oferta de nove mil ducados qual seja o dobro da quantia emprestada, após apelar para os sentimentos de misericórdia, compaixão, na espera de uma gentil posição do judeu frente ao episódio.

Animado pelo sentimento de vingança que não controla a emoção, o mutuante Schylock não aceitava os argumentos sustentados sob à luz da formação cristã. É que ao conceder o empréstimo o fez movido pelo sentimento de fatal vingança a ser executada pessoalmente contra o cristão, dado o ressentimento de ódio que nutria pelo mesmo. De maneira que mesmo os argumentos religiosos utilizados pelo 
advogado Baltasar não podiam mesmo ter o condão de sensibilizar a obstinação cega do mutuante, que insistia em querer cobrar a multa positivada na letra promissória. Nada parecia aplacar sua raiva e ódio sentidos contra o cristão, confessando, inclusive, que não tinha uma boa razão para apresentar que pudesse impedir de executar a cláusula penal. Aliás, havia jurado ao Sabá sagrado, quando do empréstimo, que faria cobrar a multa e nada o demoveria a tanto, usando como justificativa para não cometer perjúrio.

E assim se tornaram vãos os os argumentos cristãos usados contra o judeu. Por conseguinte, os próprios argumentos de misericórdia utilizados por Pórcia, disfarçada de Doutor Baltasar, no sentido de mitigar a justiça que o judeu pretendia perpetrar, não foram suficientes para aplacar sua sede e fome de justiça de exigir o cumprimento da multa e o pagamento da nota promissória. Passa então Pórcia, no caso Baltasar, a assacar os argumentos jurídicos.

Pórcia, ou Baltasar, sustentou que estava previsto na letra que seja a multa exatamente uma libra de sua carne clara, a ser cortada e tirada de qualquer parte do seu corpo que eu nominar, portanto havia a previsão precisa de uma libra de carne humana a ser tirada do corpo do fiador, nem mais nem menos. Ademais, não previra a nota promissória o derramamento de sangue do cristão, de maneira que o judeu deveria tirar exatamente uma libra de carne do cristão, sem derramar o seu sangue. A promissória dizia exatamente uma libra de carne, não previa que o credor se apropriasse do sangue do mercador.

Afigurou-se, destarte, impossível juridicamente o cumprimento da cláusula acessória, tal qual positivada na letra promissória, porquanto não haver a possibilidade de imaginar a hipótese de extrair um libra de carne de uma pessoa sem uma incisão e conseqüente derrame de sangue. Poderíamos argumentar pelo abuso de direito a ser cometido, no caso de violação da disposição contratual positivada.

\section{Conclusão}

Atentemos que ao estipular tal cláusula não se levou em consideração para outras normas existentes no ordenamento jurídico, como aquela que previa para o derramamento de uma gota de sangue cristão, o confisco das terras e de todos os bens, que passarão ao Estado pelas leis de Veneza. Havia ainda a previsão da morte 
e de confisco dos bens, no caso de tirar mais de uma libra exatamente ou menos, mesmo que seja uma diferença daquilo que se estima ser o peso de um fio de cabelo.

Por aí se vê que um texto não passa uma única significação, que os símbolos utilizados na linguagem jurídica se ressentem de incompletudes, dado aos conceitos indeterminados utilizados na linguagem jurídica, que é uma linguagem natural, por isso mesmo apresenta vagueza e ambigüidade. De modo que, o que estava claro para o judeu e no claro cessa a interpretação como sustentam os dogmáticos, para Pórcia, travestida no advogado Baltasar havia lacunas que careciam de preenchimento, razão pela qual se valeu de uma interpretação sistemática do próprio ordenamento jurídico, denunciando o problema da pragmática, o qual aponta para a dificuldade de compreensão do sentido das palavras em relação aos usuários.

E é aí que radica o problema hermenêutico. Para Schylock, cegado pelo sentimento de justiça, a cláusula inserta na nota promissória satisfazia a condição sintática e semântica de sentido, na medida em que as palavras apresentavam, respectivamente, correlação entre si e com a coisa designada, antevendo um significado unívoco. Porém, a compreensão do enunciado inserto na letra passa por uma leitura também pragmática, como aliás toda interpretação normativa, pois diz respeito à relação das palavras com os seus usuários, no caso comportando mais de um significado. E o significado da cláusula penal só pode ser buscado e apanhado, a partir de uma visão sistemática do ordenamento jurídico e não de uma norma convencional isolada.

\section{Referências Bibliográficas}

SHAKESPEARE, William. Trad. Beatriz Viégas-Faria. O mercador de Veneza. Porto Alegre: L\&PM, 2009.

(Artigo submetido em 12/12/2013 e aceito para publicação em 27/12/2013) 